Article

\title{
Hydraulic Optimization of Double Chamber Surge Tank Using NSGA-II
}

\author{
Resham Dhakal ${ }^{(}$, Jianxu Zhou *(D), Sunit Palikhe and Khem Prasad Bhattarai ${ }^{(1)}$ \\ College of Water Conservancy and Hydropower Engineering, Hohai University, Nanjing 210098, Jiangsu, China; \\ reshamdk17@gmail.com (R.D.); sunit.palikhe45@gmail.com (S.P.); kpb63@outlook.com (K.P.B.) \\ * Correspondence: jianxuzhou@163.com
}

Received: 1 January 2020; Accepted: 6 February 2020; Published: 8 February 2020

check for updates

\begin{abstract}
A surge tank effectively reduces water hammer but experiences water level oscillations during transient processes. A double chamber surge tank is used in high head plants with appreciable variations in reservoir water levels to limit the maximum amplitudes of oscillation by increasing the volume of the surge tank near the extremes of oscillation. Thus, the volume of the chambers and the design of an orifice are the most important factors for controlling the water level oscillations in a double chamber surge tank. Further, maximum/minimum water level in the surge tank and damping of surge waves have conflicting behaviors. Hence, a robust optimization method is required to find the optimum volume of chambers and the diameter of the orifice of the double chamber surge tank. In this paper, the maximum upsurge, the maximum downsurge, and the damping of surge waves are considered as the objective functions for optimization. The worst condition of upsurge and downsurge is determined through 1-D numerical simulation of the hydropower system by using method of characteristics (MOC). Moreover, the sensitivity of dimensions of a double chamber surge tank is studied to find their impact on objective functions; finally, the optimum dimensions of the double chamber surge tank are found using non-dominated sorting genetic algorithm II (NSGA-II) to control the water level oscillations in the surge tank under transient processes. The volume of the optimized double chamber surge tank is only $44.53 \%$ of the total volume of the simple surge tank, and it serves as an effective limiter of maximum amplitudes of oscillations. This study substantiates how an optimized double chamber surge tank can be used in high head plants with appreciable variations in reservoir water levels.
\end{abstract}

Keywords: numerical analysis; double chamber surge tank; method of characteristics; hydraulic transients; surge analysis; NSGA-II; reservoir water level; operation mode

\section{Introduction}

Unsteady or transient states are inevitable in any pressurized pipeline. Pressure and flow change at any point in the pressurized pipeline causes a disturbance in the steady state of the system. When a pressurized pipeline experiences a transient event, propagation of pressure waves takes place, which causes rise and fall in pressure, cavitation, vacuum, mass oscillation, etc. [1]. To control the undesired effects of hydraulic transients, many surge protection devices are widely used in pressurized pipelines. No two systems are completely identical; thus, the ultimate choice of surge protection devices and operating strategies usually differ from one system to another. Among them, a surge tank can effectively control the harmful effects of transients in the hydropower system with long water conduits.

As every system is unique with hydraulic conditions, the appropriate dimensioning of the surge tank with suitable economy is very important. When comparing two power plants with similar properties, the plant with a smaller volume surge tank is economically feasible. One of the ways to design an economic surge tank and control the effects of hydraulic transients in the hydropower system 
is to optimize the decision variables of the surge tank [2]. Decision variables of the surge tank are size and location of the surge tank, connection between the surge tank and the hydraulic system, surge tank configuration, and overflow level [3]. Researchers have extensively studied these decision variables to minimize the cost of surge tanks and to resolve the hydraulic transient problems in the systems. Kim et al. [4] applied genetic algorithm (GA) and optimized the location and the connector of the surge tank considering safety and cost of the water supply system. Adam et al. [5] carried out a 1-D numerical simulation and performed a physical scale modeling test and found that placing a throttle at the bottom of a surge tank is an effective and economical solution to adapt a hydraulic transient. Steyrer [6] compared different types of surge tanks and concluded that the economic surge tank can be achieved with an effective throttling device in connection with surge tanks. Casara et al. [7] carried out the 1-D numerical analysis and proposed the necessity of a bar grillage diaphragm at the bottom of the surge tank to ensure the minimum safety level. Shuren et al. [8] proposed the new differential surge tank with small volume and consequently minimal cost compared to the usual one. A great deal of research has been done on these decision variables to find their effects in hydraulic transients in the past few years [9-13].

Topography has a key influence in decision variables, mostly on the location of the surge tank, the surge tank configuration, and the overflow level. There is a significant variation in reservoir water level in the hydropower system in this study. Among different tank configurations, the double chamber surge tank is generally used in high head plants with appreciable variations in reservoir water level. Several attempts of comparing the double chamber surge tank with other surge tank configurations have been done in the last few years. Vereide et al. [14] compared the volume of a double chamber surge tank and an air cushion surge tank and found that the double chamber surge tank is effective for power plants with similar properties. Nabi et al. [15] carried out surge analysis for surge tanks with and without chambers and concluded that the surge tanks having one or more chamber function better than other types. Further, researchers have studied double chamber surge tanks to resolve the hydraulic transient problems in the systems. Liu et al. [16] put forward the new formula for calculating the volume of the upper chamber of the surge tank, which was more precise, reasonable, and convenient than the formula recommended by surge tank design standard. Travas [17] performed surge analysis and emphasized providing adequate dimensioning for two extensions to manipulate the surge in the double chamber surge tank. Researchers have concluded the double chamber surge tank is used to limit the maximum amplitudes of the oscillation by increasing the volume of the surge tank near the extremes of the oscillation. Thus, the arrangement of the chambers, their geometry, their volume, and the design of an orifice are the most important factors for controlling water level oscillations in a double chamber surge tank. In addition to this, maximum/minimum water level in the surge tank and damping of surge waves have conflicting behaviors. Hence, a robust optimization method is required to find the optimum volume of chambers and the diameter of the orifice of the double chamber surge tank. However, only limited work on the optimization of a chamber surge tank has been done. Further, most of these works were performed by physical scale modeling and were mainly focused on finding the volume of chambers that limits the maximum amplitudes of oscillation within a chamber. In this study, a 1-D numerical model of the given hydropower system is made using method of characteristics (MOC). Further, non-dominated sorting genetic algorithm II (NSGA-II) is used to optimize the double chamber surge tank and aims at minimizing the effects of transients in the worst conditions.

In this study, the variation of water level in the surge tank under the different cases of upsurge and downsurge are calculated and analyzed. The objective functions related to hydraulic transient and the constraints related to the design standard are developed, and optimization is carried out using NSGA-II to find the optimum volume of chambers and the diameter of the orifice of the double chamber surge tank. Further, a simple surge tank is optimized for the same value of maximum upsurge and downsurge, and the volume of optimized surge tanks is compared. Finally, the most favorable operation mode for safe and stable operation of the hydropower system is developed. 


\section{Material and Methods}

\subsection{Governing Equations}

Continuity equation and the momentum equations are the basic equations for the transient flow in closed conduits [18].

$$
\begin{gathered}
g \frac{\partial H}{\partial x}+\frac{\partial V}{\partial t}+\frac{f V|V|}{2 D}=0 \\
\frac{c^{2}}{g} \frac{\partial V}{\partial x}+\frac{\partial H}{\partial t}=0
\end{gathered}
$$

where $H$ is the piezometric head, $V$ is the mean flow velocity, $f$ is the Darcy-Weisbach friction factor, $D$ is the diameter of the pipe, $g$ is the acceleration due to gravity, and $c$ is the wave speed.

Graphical and analytical methods give the approximate solutions of these equations only for a simple system. These equations are accurately solved by the method of characteristics and can be used to analyze a large system or a system with complex boundary conditions [19].

\subsection{Method of Characteristics}

Method of characteristics transforms the continuity equation and the momentum equation into four ordinary differential equations. Later, these ordinary differential equations are solved by the finite difference method, which gives the two compatibility equations [19], Equations (3) and (4).

$$
\begin{aligned}
& H_{i}=C_{P}-B Q_{i} \\
& H_{i}=C_{M}+B Q_{i}
\end{aligned}
$$

where,

$$
\begin{gathered}
C_{P}=H_{i-1}+B Q_{i-1}-R Q_{i-1}\left|Q_{i-1}\right| \\
C_{M}=H_{i+1}-B Q_{i+1}+R Q_{i+1}\left|Q_{i+1}\right| \\
B=\frac{c}{g A} \\
R=\frac{f \Delta x}{2 g D A^{2}}
\end{gathered}
$$

where $H_{i}$ and $Q_{i}$ are the piezometric head and the discharge, respectively, at any time and space, $A$ is the area of the pipe, $f$ is the Darcy-Weisbach friction factor, $i$ is the pipe section number, and $\Delta x$ is the length of section.

Two unknown variables, $H_{i}$ and $Q_{i}$, can be easily calculated with two known compatibility Equations (3) and (4).

\subsection{Boundary Conditions}

For the given layout of the hydropower system (Figure 1), the boundary conditions proposed by Wylie [19] were considered, and the boundary conditions for the surge tank and the turbine are presented herein. 


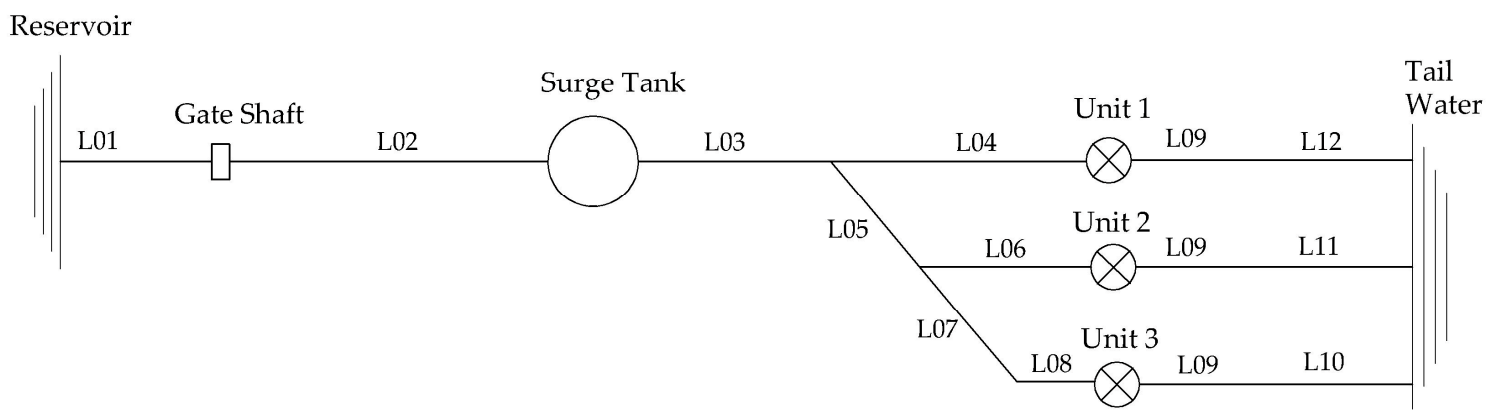

Figure 1. Layout of the hydropower system.

\subsubsection{Surge Tank}

In the given layout, the throttled double chamber surge tank is used to control the harmful effects of the transient. The chamber surge tank is a surge tank with a variable cross-section area. In other words, the area of the surge tank is the function of the water level in the surge tank.

$$
A_{S}=f\left(Z_{S}\right)
$$

The variation in the area of the surge tank is described in detail in Section 2.6. The boundary conditions of the throttled surge tank are presented below [19]:

$$
\begin{gathered}
H_{P}=Z_{S}+R_{1}\left|Q_{S}\right| Q_{S} \\
Z_{S}=R_{2}\left(Q_{S}+Q_{S O}\right)+Z_{S O} \\
Q_{1}=Q_{2}+Q_{S}
\end{gathered}
$$

where,

$$
\begin{gathered}
R_{1}=\frac{1}{2 g C_{d^{2} A_{O}{ }^{2}}} \\
R_{2}=\frac{\Delta t}{2 A_{S}}
\end{gathered}
$$

where $Q_{S}$ is the discharge into the surge tank, $Z_{S}$ is the water level in the surge tank, $H_{P}$ is the piezometric head at the bottom of the surge tank, $Q_{\mathrm{SO}}$ and $Z_{\mathrm{SO}}$ are the discharge and the water level in the surge tank, respectively, at a previous time step, $Q_{1}$ and $Q_{2}$ are the discharges in the bottom tunnel just upstream and downstream of the surge tank, respectively, $A_{O}$ is the area of the orifice, $C_{d}$ is the coefficient of discharge, and $\Delta t$ is the time step considered for simulation.

\subsubsection{Valve in Line}

This study emphasizes the water level oscillation in the surge tank. Thus, the turbine unit shown in Figure 1 can be simplified into a valve [20]. If the valve is located between two different pipelines, for the positive flow, the flow equation is given by [19]:

$$
Q_{P_{i+1, N}}=Q_{P_{i, N}}=\frac{Q_{0} \tau}{\sqrt{H_{O}}} \sqrt{H_{P_{i, N}}-H_{P_{i+1,1}}}
$$

when combined with Equation (3) and Equation (4)

$$
Q_{P_{i, N}}=-\left(B_{i}+B_{i+1}\right) C_{V}+\sqrt{\left[C_{V}\left(B_{i}+B_{i+1}\right)\right]^{2}+2 C_{V}\left(C_{P_{i}}-C_{M_{i+1}}\right)}
$$




$$
C_{V}=\frac{\left(Q_{0} \tau\right)^{2}}{2 H_{0}}
$$

where $Q_{P_{i, N}}$ is the discharge at the valve, $\tau$ is the valve opening, $Q_{O}$ is the steady state flow, and $H_{O}$ is the steady state head drop within a valve. In the double subscript notation, the first subscript denotes pipe number and the second denotes pipe section number.

\subsection{Modeling}

There are several graphical, analytical, and empirical methods used for surge analysis, but the results of these methods vary from one another [21]. In recent years, many model tests have been conducted using MOC, and researchers have established MOC as a reliable tool for accurate numerical analysis, especially for surge analysis [22-25]. Thus, for the given hydropower system (Figure 1), MOC is used to construct the 1-D numerical model in MATLAB; thereafter, analysis of the model is carried out.

The principle of the MOC is that the pipeline is divided into a number of equally long parts $(\Delta x)$, and the time step $(\Delta t)$ should be equal for all pipe segments. However, each pipe segment in a given hydropower system has different lengths and wave speeds. Thus, we select a set of $N_{j}$ and $\Delta x$ so that courant's condition is satisfied, and calculation is tabulated in Table 1.

Table 1. Pipe segments and their calculation for $\Delta t=0.01 \mathrm{~s}$.

\begin{tabular}{ccccc}
\hline Pipe Segment & Diameter $(\mathbf{m})$ & Length $(\mathbf{m})$ & No. of Segment $\left.\mathbf{( N}_{\mathbf{j}}\right)$ & $\boldsymbol{\Delta} \boldsymbol{x}(\mathbf{m})$ \\
\hline L01 & 5.5 & 236.0 & 23 & 10.26 \\
L02 & 5.5 & 3850.7 & 385 & 10.00 \\
L03 & 4.8 & 119.8 & 11 & 10.89 \\
L04 & 2.5 & 47.4 & 4 & 11.85 \\
L05 & 4.0 & 11.0 & 1 & 11.00 \\
L06 & 2.5 & 40.3 & 4 & 10.08 \\
L07 & 3.3 & 11.0 & 1 & 11.00 \\
L08 & 2.5 & 37.4 & 3 & 12.47 \\
L09 & 2.8 & 11.9 & 1 & 11.90 \\
L10 & 4.0 & 108.6 & 10 & 10.86 \\
L11 & 4.0 & 107.8 & 10 & 10.78 \\
L12 & 4.0 & 107.0 & 10 & 10.70 \\
\hline
\end{tabular}

\subsection{Objective Functions}

For controlling the water level oscillations in the surge tank under transient processes, much attention should be given in the design stage and the operational stage of the hydropower system. Upsurge, downsurge, and damping of surge waves are the basic requirements to be examined for the design of the surge tank. Thus, the basic surge requirements are taken as the objective functions for optimization.

\subsubsection{Upsurge}

The surge tank is designed to accommodate the maximum water level expected under the worst conditions. The maximum water level in the surge tank is obtained as per the code IS:7396 [26], and the worst of the following two cases is adopted:

(a) Full load rejection at once at the maximum reservoir level;

(b) Unit 1 has load acceptance at the maximum reservoir level. As the water flowing into the surge tank reaches maximum, all units have load rejection at once.

For the given hydropower system, the rated discharge for unit 1 and unit 2 is $31.9 \mathrm{~m}^{3} / \mathrm{s}$, whereas for unit 3, it is $27.54 \mathrm{~m}^{3} / \mathrm{s}$. Further, the length of penstock is shorter for unit 1; due to this, unit 1 gives the quick response of pressure wave with a maximum amplitude of oscillation in the surge tank [27]. Thus, for case $b$, initially, unit 2 and unit 3 are in normal operation and unit 1 has load acceptance 
(Figure 2). As the water flowing into the surge tank is at maximum, three units have load rejection at the same time. In this study, linear closure law is adopted, and the time for closing and opening of the valve is $8 \mathrm{~s}$, as per the closing and the opening time of the guide vane in the hydropower system.

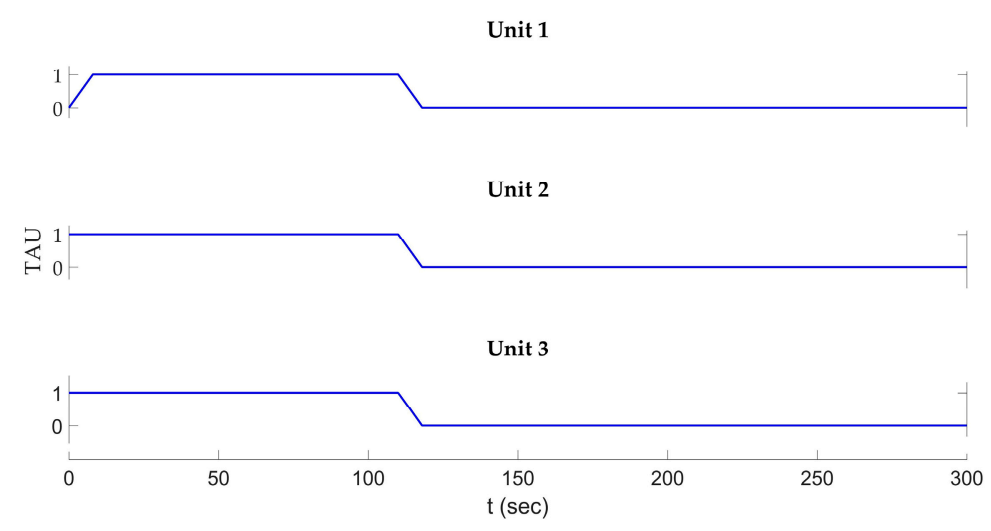

Figure 2. Valve opening for case $b$.

The maximum value of upsurge obtained from the surge analysis for two cases is adopted as the maximum water level in the surge tank. This value regulates the height of the surge tank and consequently the volume of the surge tank; thus, minimization of maximum water level is taken as the objective function in this study.

\subsubsection{Downsurge}

The surge tank is designed to accommodate the minimum water level excepted under the worst conditions. The minimum water level in the surge tank is obtained as per the code IS:7396 [26], and the worst of the following three cases is adopted:

(a) Unit 1 has load acceptance at the minimum reservoir level;

(b) Full load rejection at the minimum reservoir level;

(c) All units have load rejection at once when the water level in the reservoir is at minimum. As the water flowing out of the surge tank reaches maximum, unit 1 has load acceptance.

For case c, initially, three units have load rejection at the same time (Figure 3). As the water flowing out of the surge tank reaches maximum, unit 1 has load acceptance. The load acceptance by all units at once is often unrealistic because the load acceptance is a controllable case, and we often consider one unit with load acceptance at a time for a hydraulic system with multiple units. Further, for a given hydropower system, when all three units have load acceptance at a time during the minimum water level in the reservoir, the water level in the surge tank drops below the bottom tunnel, which indicates the problem of air entrainment. Hence, this case is not considered in this study.

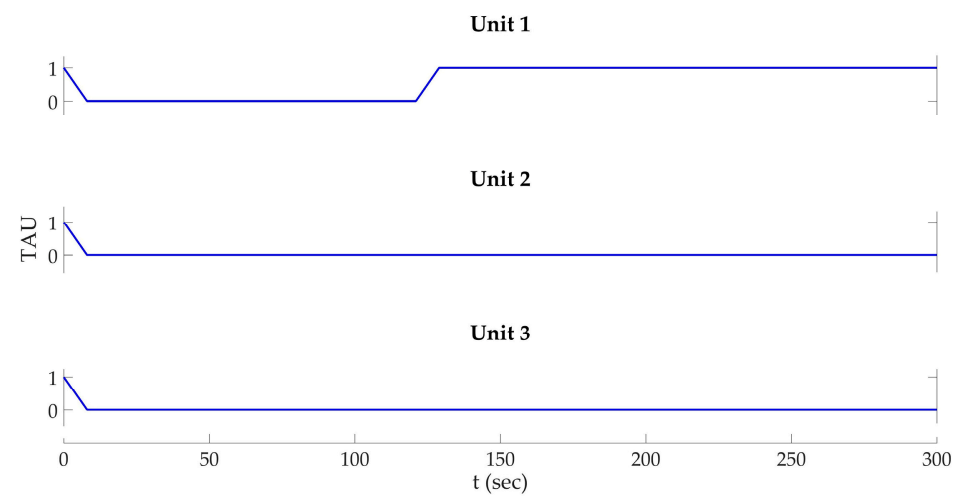

Figure 3. Valve opening for case c. 
The maximum downsurge obtained from the surge analysis for three cases is adopted as the minimum water level in the surge tank. There should be a sufficient water column in the surge tank, and the minimum water level should be above the safety level. Therefore, maximization of downsurge is taken as the objective function in this study.

\subsubsection{Damping}

Damping influences the stability of the surge tank by dragging the water level oscillations. The surge tank should be able to control the fluctuations of water level and obtain a stable level as quickly as possible. Therefore, damping of surge waves for the worst case of upsurge and downsurge is analyzed, and maximization of damping is taken as the objective function in this study. Damping is noticeably more effective in the first than in the later stages. The relationship between the amplitude of oscillation and the time is a complex exponential expression [28]. In this study, we generalize the damping equation and calculate the damping factor using Equation (18).

$$
y_{t}=y_{O} \times e^{-a t}
$$

where $y_{t}$ is the amplitude of wave at any time $t, y_{0}$ is the initial amplitude of wave, and $a$ is the damping factor. The damping factor is a dimensionless parameter that defines the oscillation in the surge tank that amplifies or dampens exponentially. The positive value of the damping factor in Equation (18) determines the exponential decrement of oscillation with time, while the negative value determines the exponential growth of oscillation with time.

To minimize the transient effects in the system, upsurge has to be minimized, while downsurge and damping have to be maximized, resulting in the mixed types of objective functions for optimization. Thus, the duality principle is used to transform the maximization problem into a minimization problem by multiplying the objective function with -1 .

\subsection{Variables and Constraints}

This study aims to optimize the double chamber surge tank and minimize the effects of transients in the worst conditions. The design of the double chamber surge tank is mostly dependent on topography and provides greater flexibility; therefore, there exists a great variety of double chamber surge tanks. In this study, the upper chamber is a cylindrical volume with a larger diameter than that of the surge shaft, whereas the lower chamber is a tunnel with a large cross-sectional area (Figure 4). Chambers are provided in the chamber surge tank to increase the volume of the surge tank near the extremes of the oscillation. Thus, the most important factors for the design of chambers in the chamber surge tank are the arrangement of the chambers, their geometry, and their volume.

During the normal operation, the water level in the surge tank is the difference of reservoir water level and head loss in the headrace tunnel. These steady state water levels govern the bottom elevation of the upper chamber and the top elevation of the lower chamber (Figure 4). Thus, the locations of the upper chamber and the lower chamber are taken as they were in the preliminary design and are not considered as a variable for optimization. The water level during normal operation remains in the surge shaft between chambers (Figure 4). The surge shaft is provided with minimum possible area required by Thoma criteria $[29,30]$ for the economic design of the chamber surge tank. Further, there should be a sufficient water column in the surge tank, and the minimum water level should be above the safety level. For this reason, the bottom elevation of the lower chamber is not considered as the variable for optimization. Therefore, diameter of orifice $\left(D_{o}\right)$, diameter of upper chamber $\left(D_{u c}\right)$, and length of lower chamber $(L)$ are considered as variables for optimization. All the fixed dimensions and variables are shown in Figure 4.

Moreover, expansion chambers are designed with an inclined top and bottom. The bottom inclination is required for dewatering at the time of inspections, while the top inclination is required for degassing. The bottom inclination of the upper chamber has a negligible effect in surge analysis; 
thus, it is neglected in this study. Due to the inclination at the lower chamber, it takes the form of frustum of cone, and the cross-sectional area of the surge tank for the lower chamber is symmetrical with the plane passing through the center of the frustum, i.e., $E L=185.5$ (Figure 4). As per the location of the lower chamber, it is modeled as the frustum of cone with radii $3.5 \mathrm{~m}$ and $3 \mathrm{~m}$. Finally, based on the variables set for the optimization, the area of the surge tank is presented in Table 2.

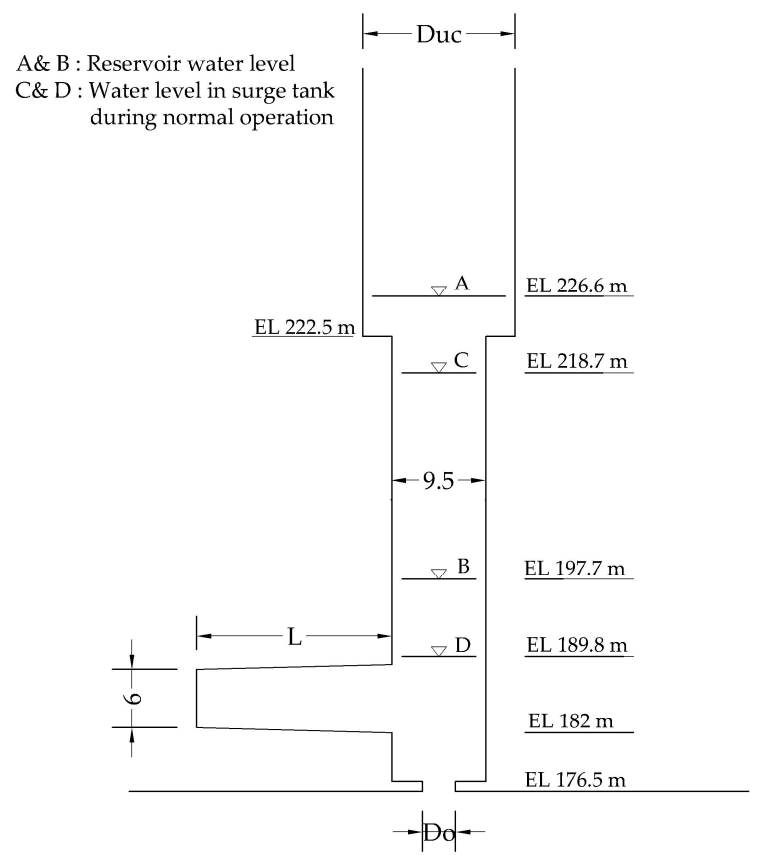

Figure 4. Variables and fixed dimensions of the double chamber surge tank.

Table 2. Variation in area of the surge tank.

\begin{tabular}{|c|c|}
\hline Water Level (m) & Area of Surge Tank $\left(\mathrm{m}^{2}\right)$ \\
\hline$Z_{S} \leq 182$ & 70.88 \\
\hline $182<Z_{S} \leq 182.5$ & $70.88+144 \times\left(Z_{S}-182\right)$ \\
\hline $182.5<Z_{S} \leq 185.5$ & $\left.70.88+L \times\left[-0.457 \times\left(Z_{S}-182\right)^{2}+2.9143\left(Z_{S}-182\right)-2.34\right)\right]$ \\
\hline $185.5<Z_{S} \leq 188.5$ & $\left.70.88+L \times\left[-0.457 \times\left(189-Z_{S}\right)^{2}+2.9143\left(189-Z_{S}\right)-2.34\right)\right]$ \\
\hline $188.5<Z_{S} \leq 189$ & $70.88-144 \times\left(189-Z_{S}\right)$ \\
\hline $189<Z_{S} \leq 222.5$ & 70.88 \\
\hline $222.5<Z_{S}$ & $0.25 \times \pi \times D_{u c}^{2}$ \\
\hline
\end{tabular}

Constraints are defined conforming to design standard and preliminary design. As per the "Design code for surge chamber (NB/T 35021)", the area of the orifice must be $25 \%-45 \%$ of the cross-sectional area of the headrace tunnel [31]. The diameter of the surge shaft is taken as the lower limit for diameter of the upper chamber $\left(D_{u c}\right)$, and the upper limit is set based on the preliminary volume calculation of the upper chamber [16,32]. Upper and lower limits for the length of the lower chamber are taken referring to the preliminary volume calculation of the lower chamber [32]. In addition to these, at the time of the worst upsurge, the maximum piezometric head in the bottom tunnel at the orifice due to water hammer should be nearly equal to the maximum rise of the water level in the upper chamber of the surge tank [26,31]. In this study, the difference between the maximum piezometric head and the maximum water level is allowed to be less than or equal to $1 \mathrm{~m}$. Furthermore, for the safety of the hydropower system from harmful vortices or air entrainment, a sufficient water column in surge tank has to be provided, and the safety level has to be maintained. Based on these requirements, the 
minimum water level in the surge tank for a given hydropower system in any condition should be equal to or greater than $183 \mathrm{~m}$. Hence, we have:

- $2.62 m \leq D_{O} \leq 3.8 m$

- $9.5 m \leq D_{u c} \leq 14 m$

- $17 m \leq \mathrm{L} \leq 22 m$

- $\max \left(H_{P}\right)-\max \left(Z_{S}\right) \leq 1 m$

- $\min \left(Z_{S}\right) \geq 183 m$

\subsection{NSGA-II}

There are many multi-objective evolutionary algorithms, and it is a major challenge for scientists and researchers to select the most suitable algorithm. Further, existing multi-objective evolutionary methods have been modified, mitigating their shortcomings. With addressing all the limitations of NSGA, Deb [33] developed an improved NSGA called NSGA-II. It incorporates elitisms, non-domination, and an explicit diversity preserving mechanism, which are essential features for evolutionary methods to find the Pareto set of solutions. Many researchers have performed a detailed analysis and numerical simulation on several test problems for the comparison of evolutionary algorithms and concluded NSGA-II is a better evolutionary algorithm based on overall performance [34-38]. The optimization features of NSGA-II are adequate for our problem, and it also provides comparatively better performance than other multi-objective evolutionary algorithms, thus it is taken for optimization of the double chamber surge tank. NSGA-II mainly consists of six steps: initialization (setting parameters and generating the initial population), fast non-dominated sorting, crowding distance calculation, genetic operators (crossover and mutation), non-dominated sorting, recombination, and selection [33]. These steps are presented in sequential order in Figure 5.

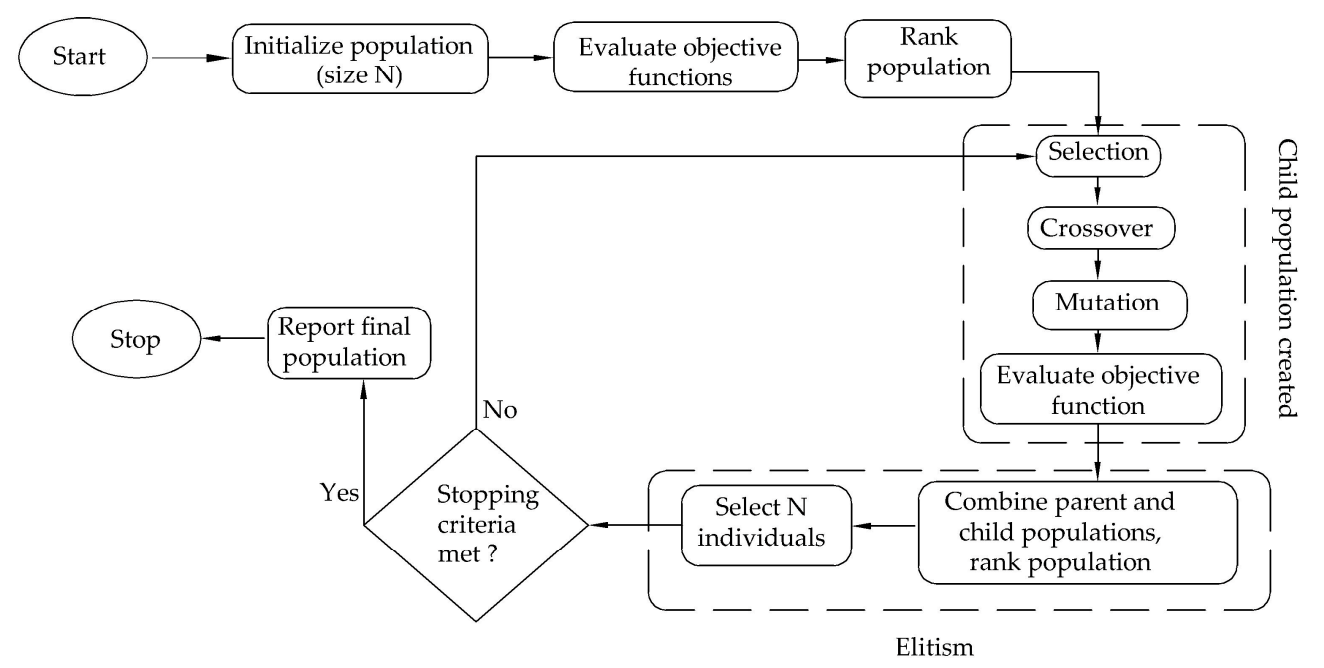

Figure 5. Flowchart of non-dominated sorting genetic algorithm II (NSGA-II).

The parameters of NSGA-II mainly consist of the population size, the crossover and mutation probabilities, and the maximum number of generations. In this study, initial population is assigned by taking a random parent population size of 40 . Due to the small search space, a small population size is considered. Crossover is a convergence operation that guides population towards local minima or maxima, whereas mutation is a divergence operation that preserves genetic diversity and evades the early convergence on local minima or maxima. Since the aim is to bring the population to convergence, crossover should occur more frequently and mutation less frequently. Thus, in this study, crossover probability and mutation probability are taken as $90 \%$ and $10 \%$, respectively. The values of crossover distribution index and mutation distribution index determine the closeness of generated offspring to 
their parent populations. The large distribution index value provides a greater probability to produce offspring similar to parents, resulting in a lack of diversity in generated offspring [33]. Hence, in this study, distribution index values are taken as two.

Elitism is a phenomenon applied in evolutionary methods to preserve elites of a population. The populations of offspring and parents population are combined, and the best required number of populations is selected based on their fitness value. Therefore, a good solution obtained early does not get lost until the better solution is discovered in coming generations. The evolutionary multi-objective optimization methods give only the Pareto optimal sets of the solution. However, it is not enough, and the decision maker still needs to select the single best solution out of that set.

As the ideal point method includes simple distance calculation and reduces the computational time and complexity, it is most widely used as a post optimal technique $[39,40]$. After obtaining the Pareto front from NSGA-II, among various post optimal techniques, ideal point method is used for selection of the optimum solution from the Pareto front. Finally, the number of generations should be greater than 100, and the optimum solution that must repeat five times in consecutive generations are taken as stopping criteria.

\section{Results and Discussions}

\subsection{Surge Analysis}

The preliminary dimensions of $D_{0}, D_{u c}$ and $L$ are $3.1 \mathrm{~m}, 11.5 \mathrm{~m}$, and $19.5 \mathrm{~m}$, respectively. The highest reservoir water level and the lowest reservoir water level are $226.6 \mathrm{~m}$ and $197.7 \mathrm{~m}$, respectively. For a hydropower plant with appreciable variations in reservoir water level, surge should be analyzed separately for the lowest and the highest reservoir levels.

Water levels in the surge tank for different cases of upsurge described in Section 2.5.1 are shown in Figure 6. Thus, the maximum value of surge head shown by the graph reveals the maximum water level in the surge tank. In the first $10 \mathrm{~s}$, the water level in the surge tank is stable, which reflects the steady state condition. After $10 \mathrm{~s}$, acceptance and rejection of load are done, as described in Section 2.5.1 for different cases of upsurge. For case a, after $10 \mathrm{~s}$, all three units have load rejection at the same time, whereas, for case $b$, all three units have load rejection at the instant of maximum water flowing into the surge tank, i.e., 120.19 s. Water level in the surge tank raises slowly to its maximum value and oscillates to its consecutive maximum and minimum values due to mass oscillation. The comparison of the maximum value of surge head indicates case $b$ is the critical case for upsurge with a value of surge head $254.34 \mathrm{~m}$. Further, the damping of the surge waves occurs very slowly during upsurge and should be analyzed properly.

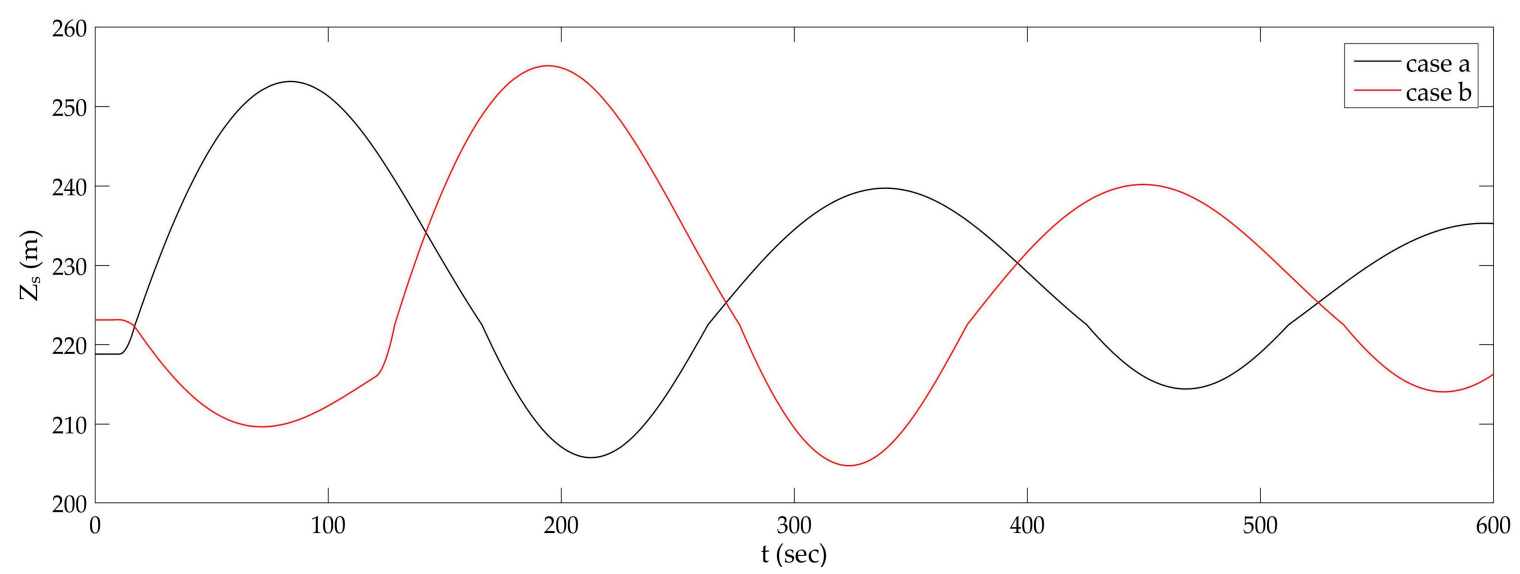

Figure 6. Water level in the surge tank for different cases of upsurge described in Section 2.5.1. 
Similarly, Figure 7 displays the water level in the surge tank for different cases of downsurge described in Section 2.5.2. Hence, the minimum value of surge head shown by the graph reveals the minimum water level in the surge tank. In the first $10 \mathrm{~s}$, the water level in the surge tank is stable, which reflects the steady state condition. After $10 \mathrm{~s}$, acceptance and rejection of load are done, as described in Section 2.5.2 for different cases of downsurge. For case a, unit 1 has load acceptance after $10 \mathrm{~s}$. For case $\mathrm{b}$, all three units have load rejection at the same time during minimum water level in the reservoir. For case c, unit 1 has load acceptance at 131.34 s, i.e., a moment of maximum water flowing out of the surge tank. Water level in the surge tank drops to its minimum value and oscillates to its consecutive minimum and maximum values due to mass oscillation. Water level in the surge shaft falls steeply, but surges are confined by the lower chamber. Due to this, the surge is almost horizontal in the region of the lower chamber (Figure 7). However, the minimum water level for case $c$ is below the bottom elevation of the lower chamber, which indicates the lower chamber fails to act as an effective limiter of the maximum amplitudes of the oscillation. Further, a water column of sufficient height has to be provided to prevent the formation of vortex in the system. Thus, the minimum water level in the surge tank has to be raised. Also, damping of surge wave occurs very slowly during downsurge and should be analyzed properly.

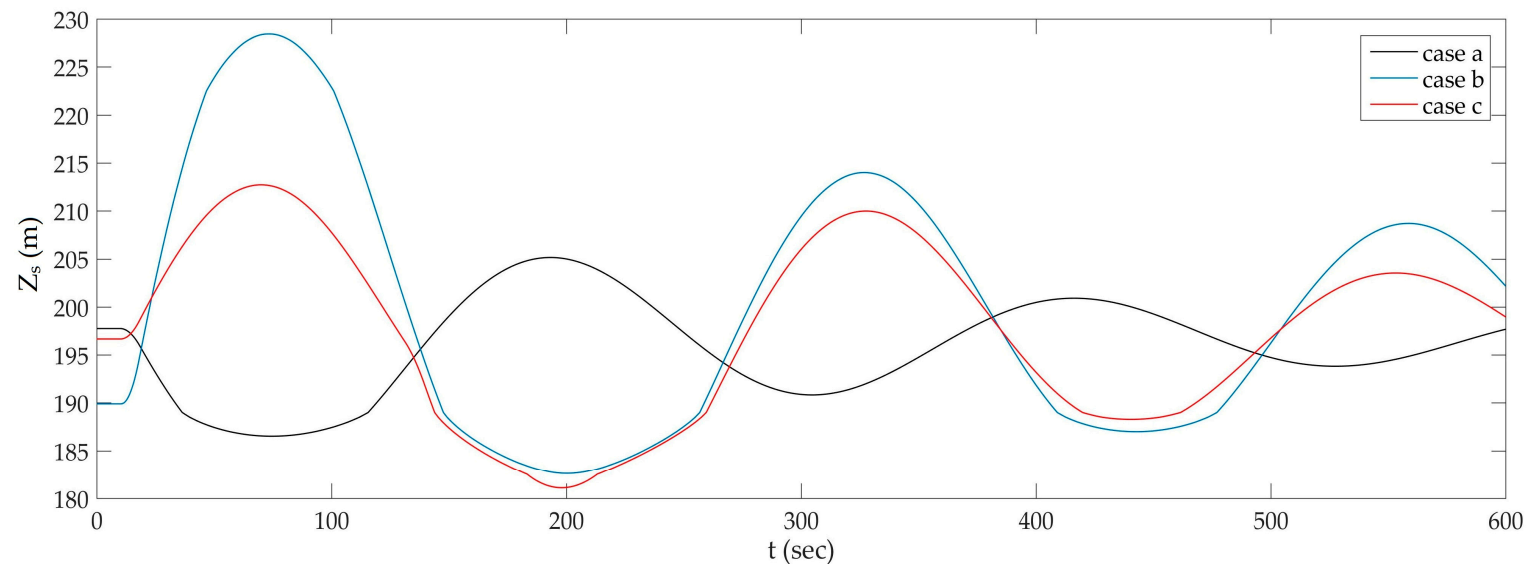

Figure 7. Water level in the surge tank for different cases of downsurge described in Section 2.5.2.

\subsection{Sensitivity Analysis}

The upper chamber and the lower chamber have to serve as effective limiters of the maximum amplitudes of oscillation and obtain a stable level as quickly as possible. Hence, a more in-depth study on variables is necessary to identify their impacts on objective functions. Thus, the sensitivity analysis is carried out for the worst case of downsurge and upsurge. The sensitivity of minimum water level and the damping of the surge waves during downsurge is analyzed with varying diameter of orifice $\left(D_{o}\right)$, diameter of upper chamber $\left(D_{u c}\right)$, and length of lower chamber $(L)$, as shown in Figure 8 . When the $D_{o}$ is increased, the minimum water level and the value of damping factor decrease. The straight line in Figure 8b,e indicate the upper chamber does not have any effect on downsurge. As the length of the lower chamber $(L)$ is increased, the minimum water level gradually increases, whereas the value of the damping factor gradually decreases. Similarly, the sensitivity of the maximum water level and the damping of the surge waves during upsurge are analyzed with varying $D_{O}, D_{\mathcal{u c}}$, and $L$, as shown in Figure 9.

As the $D_{o}$ is increased, the value of maximum water level increases, whereas the value of damping factor decreases (Figure 9). As the $D_{u c}$ is increased, the values of maximum water level and damping factor gradually decrease. The straight line in Figure $9 \mathrm{c}, \mathrm{f}$ indicate the lower chamber does not have any effect on upsurge. 


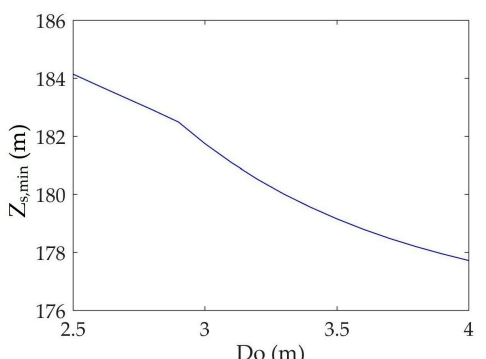

(a)

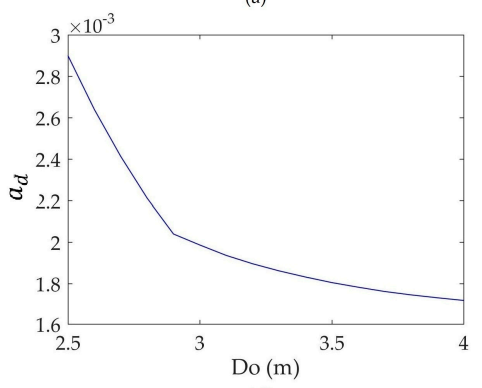

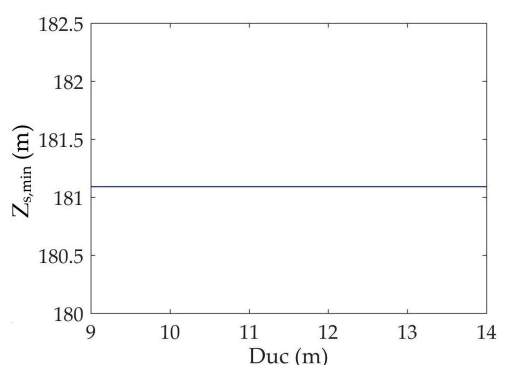

(b)

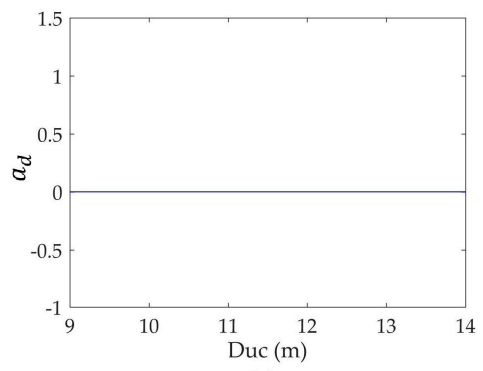

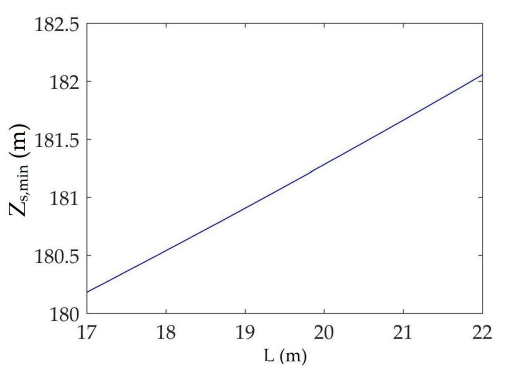

(c)

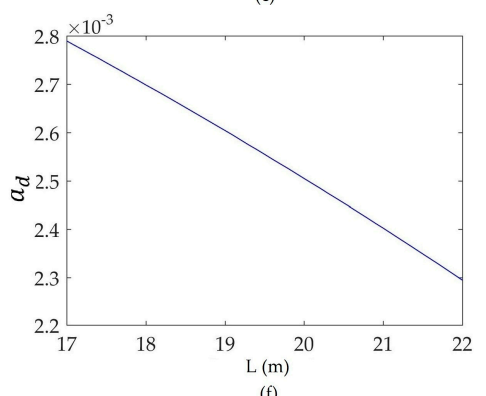

Figure 8. Minimum water level $(\mathbf{a}-\mathbf{c})$ and damping factor $(\mathbf{d}-\mathbf{f})$ for different diameters of orifice $(D o)$, diameters of upper chamber $(D u c)$, and length of lower chamber $(L)$.
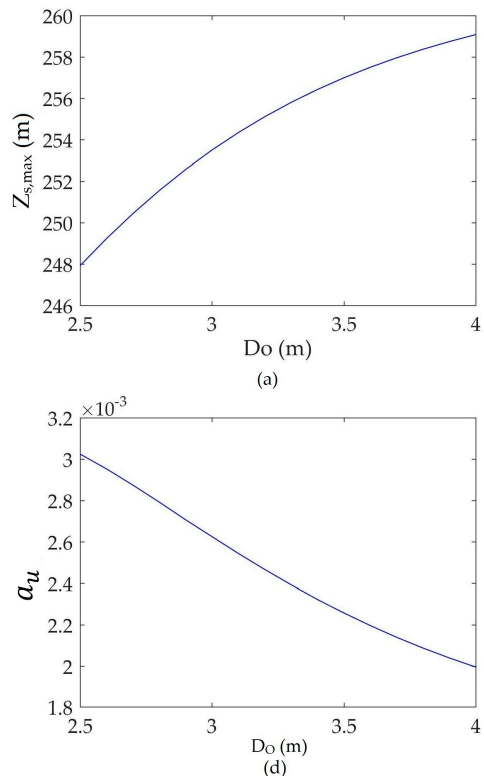

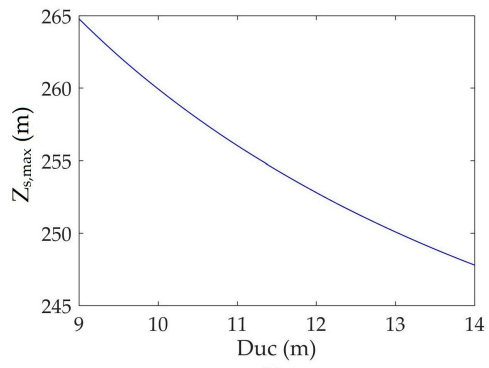

(b)

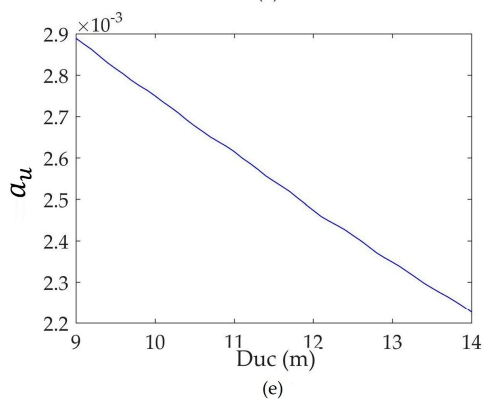

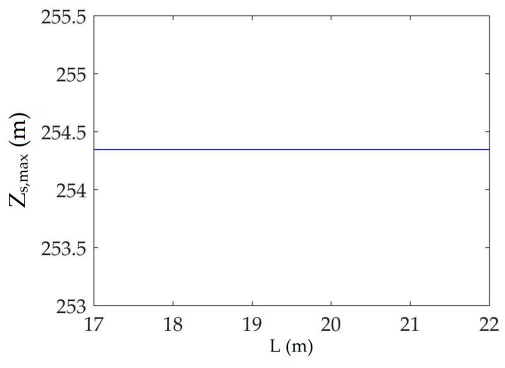

(c)

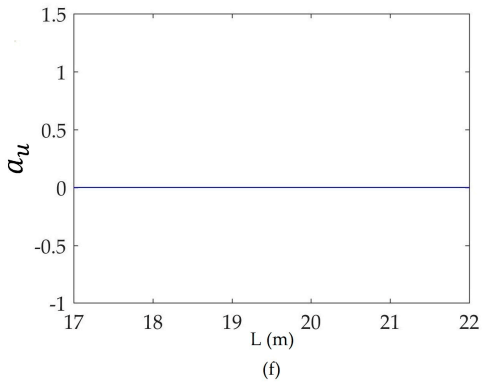

Figure 9. Maximum water level $(\mathbf{a}-\mathbf{c})$ and damping factor $(\mathbf{d}-\mathbf{f})$ for different diameters of orifice $(D o)$, diameters of upper chamber $(D u c)$, and length of lower chamber $(L)$.

All objective functions are transformed into a minimization problem, and the slope of the sensitivity curve is calculated and presented in Table 3 . In every column, the sensitivity of the $D_{o}$ is higher, which means it has more impact on objective functions (Table 3). From the analysis, it is clear that the diameter of the upper chamber $\left(D_{u c}\right)$ does not have any effect on the minimum water level or the damping factor during downsurge and, similarly, the length of the lower chamber $(L)$ does not have any effect on the maximum water level or the damping factor during upsurge. For the economic design and limiting the extreme surges, chambers are fixed on extremes of oscillation. Therefore, the effects of the lower chamber on upsurge and the upper chamber on downsurge are not seen in the sensitivity analysis. 
Table 3. Sensitivity: slope of sensitivity curve.

\begin{tabular}{ccccc}
\hline \multirow{2}{*}{ Variable } & \multicolumn{2}{c}{ Upsurge } & \multicolumn{2}{c}{ Downsurge } \\
\cline { 2 - 5 } & $Z_{S, \text { max }}$ & $a_{\boldsymbol{u}}$ & $Z_{S, \text { min }}$ & $\boldsymbol{a}_{\boldsymbol{d}}$ \\
\hline$D_{o}$ & 7.3 & 0.0006 & 4 & 0.0007 \\
$D_{u c}$ & -3.6 & 0.0001 & 0 & 0 \\
$\mathrm{~L}$ & 0 & 0 & -0.36 & 0.0001 \\
\hline
\end{tabular}

The common variable for upsurge and downsurge is $D_{O}$, and the positive value of sensitivity in Table 3 indicates the lower value of $D_{O}$ is favorable for all the objectives functions, which was also concluded by many researchers $[5,6,11]$. Damping of surge waves is due to the frictional loss in the headrace tunnel and the surge tank during mass oscillation. The lower value of the diameter of the orifice induces more friction loss, resulting in a favorable case for damping. Similarly, the small diameter of the orifice restricts the volume of the inflow and the outflow through the surge tank and consequently decreases the surge amplitude. Hence, a lower value of $D_{o}$ is favorable for maximum water level and minimum water level. On the other hand, it increases water hammer pressure in the bottom tunnel. However, at the time of the worst upsurge, the maximum piezometric head in the bottom tunnel at orifice due to water hammer should be nearly equal to the maximum rise of water level in the upper chamber of the surge tank. Therefore, $D_{o}$ and $D_{u c}$ have to be optimized to find the optimum ratio between the pressure amplitudes from the water hammer and the mass oscillations. Further, the maximum water level and the damping of surge during upsurge conflict with variable $D_{u c}$ (Table 3). Thus, in the first instance, only maximum water level and damping factor for upsurge are taken as objective functions, and optimization is done.

$$
\begin{gathered}
F_{1}: \min Z_{S, \max }\left(D_{o}, D_{u c}\right) \\
F_{2}: \max a_{u}\left(D_{o}, D_{u c}\right)
\end{gathered}
$$

After that, with the optimized values of $D_{O}$ and $D_{u c}$, optimization between minimum water level and damping factor for downsurge is done.

$$
\begin{gathered}
F_{1}: \max Z_{S, \min }(L) \\
F_{2}: \max a_{d}(L)
\end{gathered}
$$

\subsection{Optimization}

In the first instance, optimization is carried out taking maximum water level and damping factor for upsurge as the objective functions. Maximization of the damping factor is reduced to a minimization problem using duality principle. The Pareto front obtained for the maximum water level in the surge tank and the damping factor for upsurge are shown in Figure 10.

This graph illustrates the minimum values of maximum water level and damping factor cannot be achieved at the same point. Moving from left to right of the graph, maximum water level increases, whereas damping factor decreases. This curve reflects the conflicting nature of damping factor and maximum water level during upsurge. Hence, NSGA-II is used to obtain the non-dominated set of values for damping factor and maximum water level. In each generation, the best-compromised solution is chosen from the non-dominated set of solutions using the ideal point method. Based on the stopping criteria, the final result of optimization is presented in Table 4. Further, the sensitivity analysis is carried out taking a different size of initial population, and the results are tabulated in Table 4 . The sensitivity analysis confirms that the values of the objective functions and the variables are almost the same for different population size. 


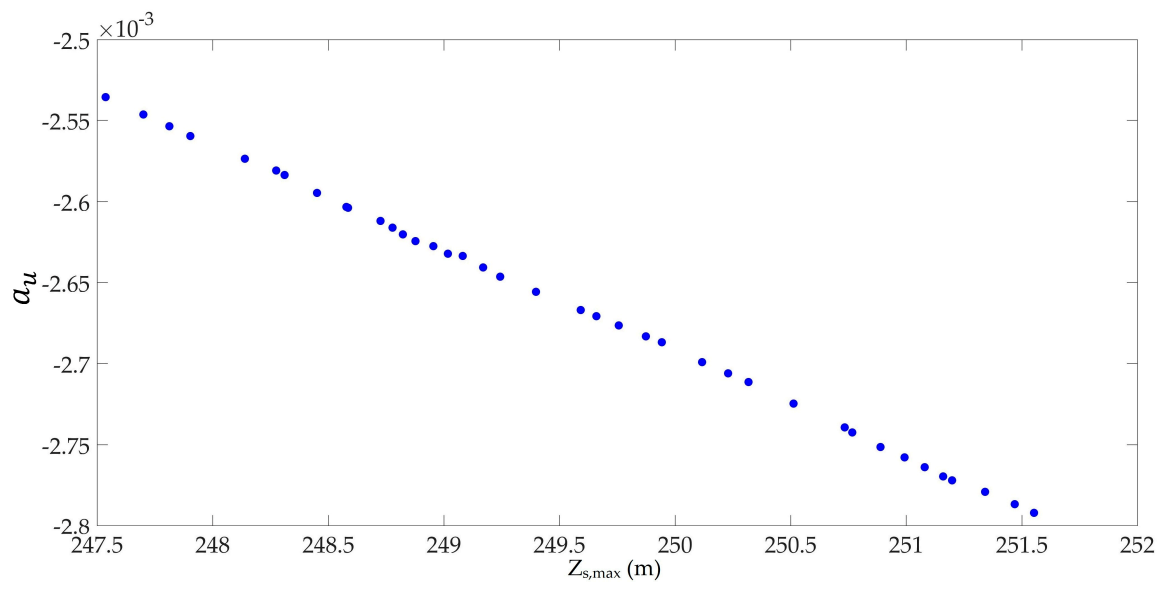

Figure 10. Pareto front for upsurge.

Table 4. Sensitivity analysis with different population size.

\begin{tabular}{|c|c|c|c|c|c|c|c|c|c|}
\hline \multirow{3}{*}{ Opt. } & \multirow{3}{*}{ Pop. No. } & \multirow{2}{*}{\multicolumn{3}{|c|}{ Variable }} & \multicolumn{4}{|c|}{ Objective Function } & \multirow{3}{*}{ Gen } \\
\hline & & & & & \multicolumn{2}{|c|}{ Upsurge } & \multicolumn{2}{|c|}{ Downsurge } & \\
\hline & & $D_{O}(\mathrm{~m})$ & $D_{u c}(\mathrm{~m})$ & $L(\mathrm{~m})$ & $Z_{S, \max }(\mathrm{m})$ & $a_{u}$ & $Z_{S, \text { min }}(\mathrm{m})$ & $a_{d}$ & \\
\hline \multirow{3}{*}{ I } & 30 & 2.81 & 12.30 & & 249.374 & 0.002648 & & & 135 \\
\hline & 40 & 2.80 & 12.26 & & 249.400 & 0.002656 & & & 105 \\
\hline & 50 & 2.80 & 12.23 & & 249.419 & 0.002657 & & & 115 \\
\hline \multirow{3}{*}{ II } & 30 & & & 20.04 & & & 183.254 & 0.002372 & 120 \\
\hline & 40 & & & 20.00 & & & 183.245 & 0.002375 & 109 \\
\hline & 50 & & & 20.17 & & & 183.275 & 0.002365 & 165 \\
\hline
\end{tabular}

In the second instance, optimization is carried out taking $L$ as the variable and minimum water level and damping factor for downsurge as the objective functions. These objective functions are transformed into a minimization problem using the duality principle. The Pareto front obtained for the minimum water level in the surge tank and the damping factor for downsurge are shown in Figure 11. This curve reveals the conflicting nature of damping factor and minimum water level during downsurge. Optimization is done in the same way as the first optimization, and the final result of optimization is presented in Table 4. Further, the sensitivity analysis is carried out taking a different size of initial population, and the results are tabulated in Table 4 . The sensitivity analysis confirms that the values of the objective functions and the variables are almost the same for different population size.

The optimized dimensions of the double chamber surge tank produce notable improvements in the maximum water level and the minimum water level of $4.942 \mathrm{~m}$ and $2.155 \mathrm{~m}$, respectively, and negligible improvements in the damping factor during upsurge and downsurge of 0.0001 and 0.0004 , respectively. Although water level and damping factors have conflicting nature with variables $D_{u c}$ and $L$, the negligible improvement in the damping factor is due to the impact of the decrease in $D_{O}$, as $D_{O}$ is more sensitive to objective function (Table 3). For the optimized dimensions, the values of the extreme surge are limited within chambers, which means chambers serve as effective limiters of maximum amplitudes of oscillation. Further, the piezometric head at the bottom tunnel and the water level in the surge tank before optimization and after optimization for the critical case of upsurge are shown in Figure 12. The maximum piezometric heads at the bottom tunnel of the surge tank before optimization and after optimization are $254.342 \mathrm{~m}$ and $249.390 \mathrm{~m}$, respectively. The improvements in the maximum water level and the piezometric head after optimization are $4.942 \mathrm{~m}$ and $4.95 \mathrm{~m}$, respectively. After optimization, the difference between the maximum piezometric head in the bottom tunnel at the orifice and the maximum water level in the upper chamber of a surge tank is only 0.0092 $\mathrm{m}$, and the graphs for these two heads are almost overlapping, which attests to the sound functioning of the double chamber surge tank. 


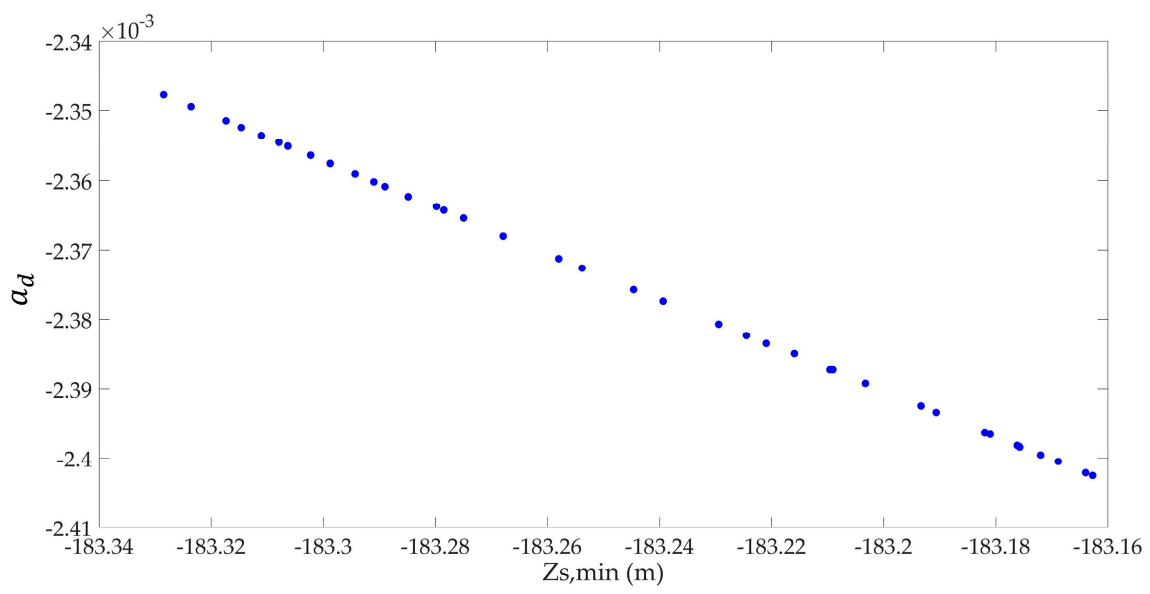

Figure 11. Pareto front for downsurge.

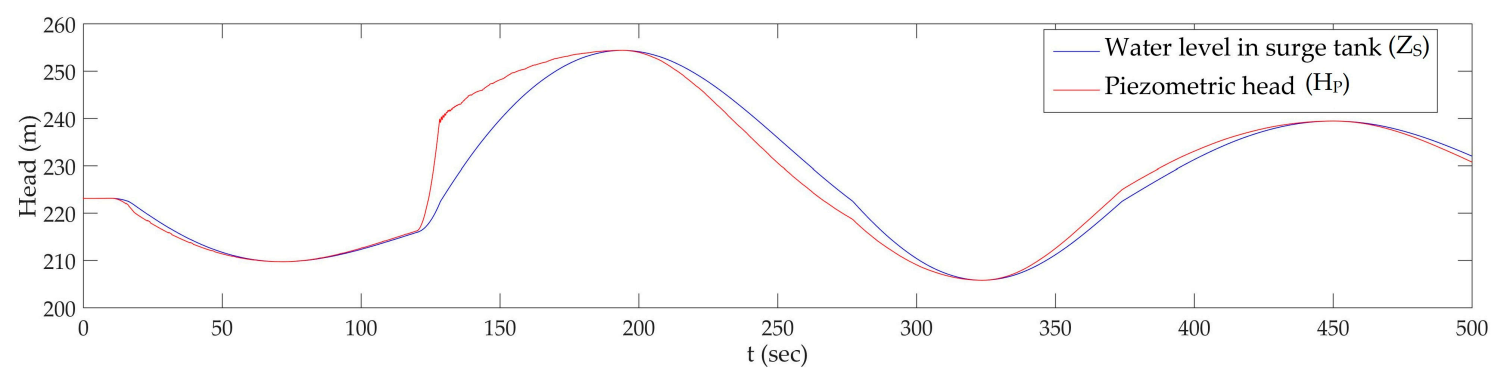

(a)

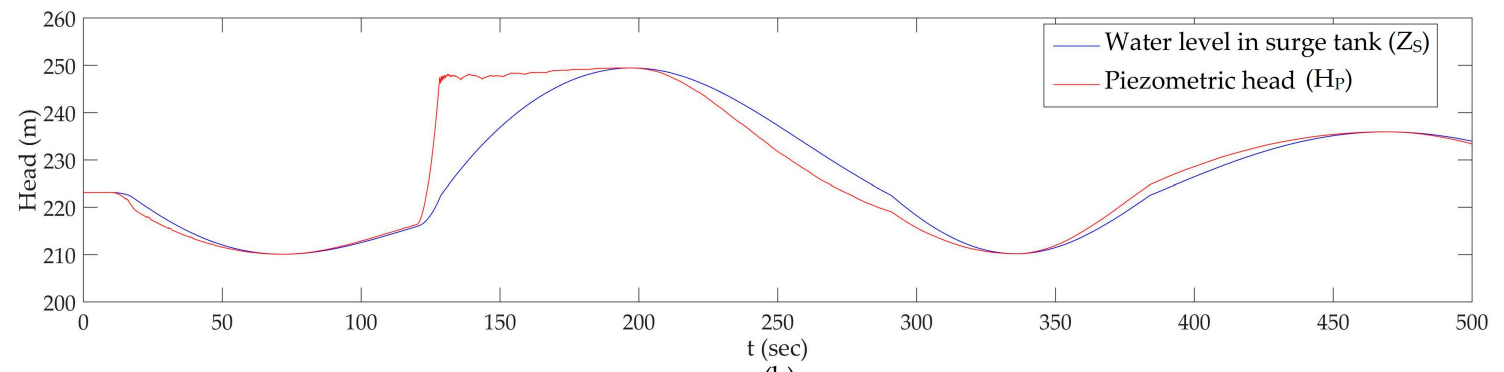

(b)

Figure 12. Piezometric head at the bottom tunnel of the surge tank and the water level in the surge tank before optimization (a) and after optimization (b)

Moreover, when comparing two hydropower plants with similar properties, the plant with a smaller volume in a surge tank is economically feasible. Maximum water level, minimum water level, damping of surge waves, and total volume of surge tank are the main decisive parameters for the selection of the type of surge tank. Therefore, a simple surge tank is optimized to get the same value of maximum water level and minimum water level. The optimized dimensions and the water levels for both surge tanks are tabulated in Table 5, and the volume obtained is analyzed.

Table 5. Comparison of total volume of optimized surge tanks: SST = simple surge tank, DCST = double chamber surge tank.

\begin{tabular}{ccc}
\hline \multirow{2}{*}{ Objective Function } & SST & DCST \\
\cline { 2 - 3 } & $\boldsymbol{D}_{\boldsymbol{s}}=16.70 \mathbf{m}$ & $\mathbf{D}_{\boldsymbol{o}}=2.8 \mathbf{m}, \boldsymbol{D}_{\boldsymbol{u c}}=12.26 \mathbf{m}$ and $\mathbf{L}=20 \mathbf{~ m}$ \\
\hline Upsurge $(\mathrm{m})$ & 248.427 & 249.400 \\
Downsurge $(\mathrm{m})$ & 183.245 & 183.245 \\
Volume $\left(\mathrm{m}^{3}\right)$ & 16208.9 & 7219.1 \\
\hline
\end{tabular}


The total volume of the double chamber surge tank is only $44.53 \%$ of the total volume of the simple surge tank (Table 5). The damping factors of the simple surge tank for upsurge and downsurge are 0.0011 and 0.0020 , respectively, both of which are less than that of the double chamber surge tank. Hence, by providing effective throttling and with an optimum volume of chambers, damping can be improved, and a huge amount of volume can be reduced. Further, the larger the difference in reservoir water levels is, the more the height of the central part with minimum area becomes, resulting in a decrease in the total volume of the chamber surge tank. This implies that the variations in the reservoir water levels are associated with the economy and the efficiency of the double chamber surge tank.

\subsection{Operational Stage}

In the hydropower plant with multiple units, each unit has its own operating requirements; consequently, the superposition of water level in the surge tank is unavoidable [41,42]. Thus, controlling the water level oscillation in the surge tank for the hydropower plant with multiple units is a major issue. Further, there is a large variation in reservoir water levels; thus, the most effective operation mode should be adopted to limit the amplitude of surge in the surge tank.

Moreover, some hydropower systems are not designed considering load acceptance by many turbines at once during dead water level in the reservoir. Hence, for safe and stable operation of the hydropower system during dead water level in the reservoir, the operation of units should be done carefully. Further, a sufficient water column in the surge tank has to be provided, and the safety level has to be maintained. Based on these requirements, the minimum water level in the surge tank for a given hydropower system in any condition should be equal to or greater than $183 \mathrm{~m}$. Relying on this, an optimal accepting rule for units is developed and is shown in Figure 13. It indicates the minimum water level in the surge tank and the time difference have an almost linear relationship. From this graph, it is clear that the minimum time lag between load acceptance of unit 1 and unit 2 is $60 \mathrm{~s}$, and the minimum time lag between load acceptance of unit 2 and unit 3 is $76 \mathrm{~s}$. Based on this minimum time difference, acceptance of load is done, and the water level in the surge tank is shown in Figure 14. The valve opening time for all the cases taken is $8 \mathrm{~s}$.

When all three units have load acceptance at a time during the minimum water level in the reservoir, the water level drops below the bottom tunnel, i.e., $176.5 \mathrm{~m}$, which indicates the problem of air entrainment. Air should be prevented from entering the penstock, even in the case of the deepest downsurge; moreover, to prevent vortex formation, ample water cover should be maintained. Thus, the minimum water level in the surge tank can be controlled by the acceptance of load in multiple stages, as shown in Figure 14.

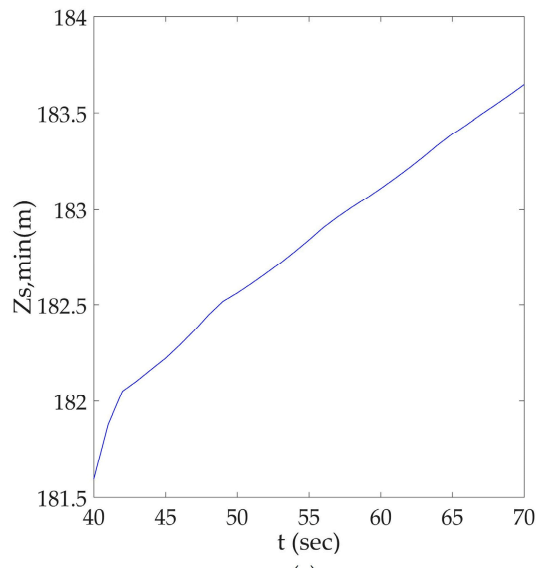

(a)

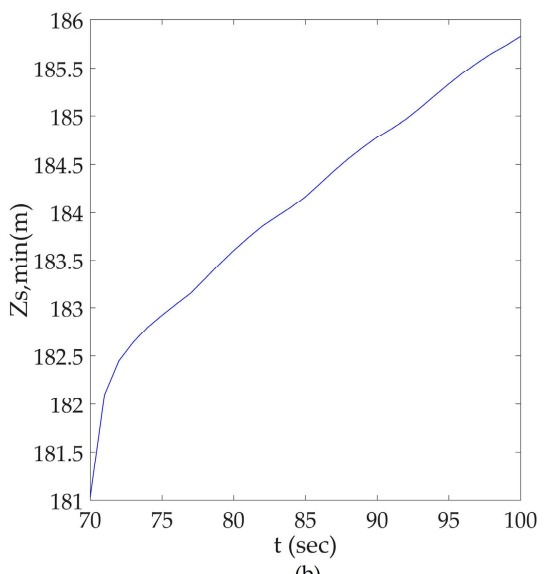

(b)

Figure 13. Time lag for the load acceptance by unit 2 (a) and unit 3 (b). 


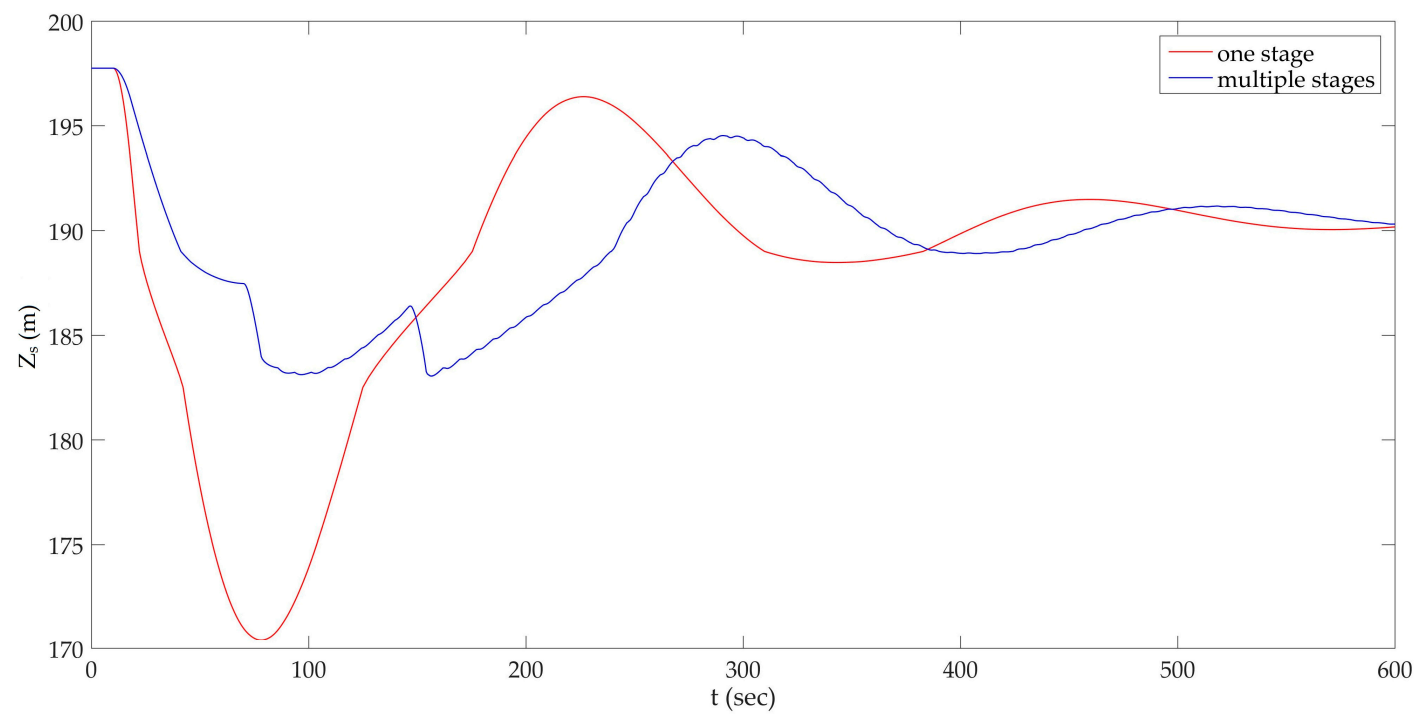

Figure 14. Killing surge by acceptance of load in three stages.

\section{Conclusions}

For controlling the water level oscillations in the surge tank under transient processes, much attention should be given in the design stage and the operational stage of the hydropower system. Upsurge, downsurge, and damping of surge waves are the basic requirements to be examined for the design of the surge tank. Thus, the basic surging conditions were analyzed by 1-D numerical modeling of a given hydropower system using MOC. Among various operational conditions in the operational stage of the hydropower system, the water level in the surge tank and the damping of the surge waves during the worst case for upsurge and downsurge were taken as the objective functions for optimization. From this study, the following conclusions are drawn:

1. Steady state water level and safety criteria governed the location of the lower chamber and the upper chamber. The surge shaft was provided with a minimum possible area required by Thoma criteria for the economic design of the chamber surge tank. Thus, diameter of orifice $\left(D_{o}\right)$, diameter of upper chamber $\left(D_{u c}\right)$, and length of lower chamber $(L)$ were taken as the variables for optimization of the double chamber surge tank;

2. Sensitivity analysis of these variables shows that $D_{u c}$ did not have any effect in downsurge, and $L$ did not have any effect in upsurge. Water level in the surge tank and damping of surge waves during downsurge and upsurge had conflicting behaviors for $D_{u c}$ and $L$, whereas the lower value of $D_{o}$ was favorable. Further, the calculation of sensitivity indicated the $D_{o}$ was more sensitive on objectives functions. However, at the time of the worst upsurge, to maintain the maximum piezometric head in the bottom tunnel at the orifice and the maximum water level in the upper chamber of the surge tank at nearly equal levels, $D_{o}$ and $D_{u c}$ had to be optimized to find the optimum ratio between the pressure amplitudes from the water hammer and the mass oscillations;

3. The NSGA-II optimized the values of $D_{o}, D_{u c}$, and $L$ with a notable improvement in maximum and minimum water levels in the double chamber surge tank with viable damping of surge waves. The double chamber surge tank served as an effective limiter of maximum amplitudes of oscillation. Further, the total volume of the optimized double chamber surge tank was only $44.53 \%$ of the total volume of the simple surge tank. Hence, by providing effective throttling with an optimum volume of chambers, damping could be improved, and a huge amount of volume of surge tank could be decreased; 
4. In the hydropower system with multiple units, controlling the water level oscillation in surge tank is a major issue. The most effective operation mode should be adopted to limit the amplitude of surge in the surge tank. Surge can be killed by acceptance of load in multiple stages.

This study optimized the double chamber surge tank and could be the cornerstone for the hydraulic optimization of the double chamber surge tank. In future research, arrangement of chambers and area of central surge shaft could be included in optimization. Research on modification in the shape of an expansion chamber for minimizing hydraulic transient could be an attractive subject for future work.

Author Contributions: Conceptualization, R.D. and J.Z.; Methodology, R.D., S.P. and K.P.B.; Formal analysis, R.D.; Writing —original draft preparation, R.D.; Writing—-review and editing, R.D., J.Z., S.P. and K.P.B.; Supervision, J.Z. All authors have read and agreed to the published version of the manuscript

Funding: This research was supported by the National Natural Science Foundation of China (Grant No. 51479071), the National Key R \& D Program of China (Grant No. 2016YFC0402501), and the Priority Academic Program Development of Jiangsu Higher Education Institutions (PAPD, SYS1401).

Conflicts of Interest: The authors declare no conflict of interest.

\section{References}

1. Boulos, P.F.; Karney, B.W.; Wood, D.J.; Lingireddy, S. Hydraulic Transient Guidelines. J. Am. Water Resour. Assoc. 2005, 97, 111-124. [CrossRef]

2. Kendir, T.E.; Ozdamar, A. Numerical and experimental investigation of optimum surge tank forms in hydroelectric power plants. Renew. Energy 2013, 60, 323-331. [CrossRef]

3. Pejovic, S.; Boldy, A.P.; Obradovic, D. Guidelines to Hydraulic Transient Analysis; Gower Technical: Randolph, VT, USA, 1987; ISBN 0291397239.

4. Kim, S.H. Design of surge tank for water supply systems using the impulse response method with the GA algorithm. J. Mech. Sci. Technol. 2010, 24, 629-636. [CrossRef]

5. Adam, N.J.; De Cesare, G.; Nicolet, C.; Billeter, P.; Angermayr, A.; Valluy, B.; Schleiss, A.J. Design of a throttled surge tank for refurbishment by increase of installed capacity at a high-head power plant. J. Hydraul. Eng. 2018, 144, 1-10. [CrossRef]

6. Peter, S. Economic surge tank design by sophisticated hydraulic throttling. In Proceedings of the 28th IAHR congress, Graz, Austria, 22-27 August 1999.

7. Cesare, G. De Surge tank geometry modification for power increase. In Proceedings of the Hydro Conference 2015, Bordeaux, France, 26-28 October 2015.

8. Wang, S.; Liu, T.; Zou, W.; Peng, T.; Xu, K. Advantage of new differential surge chamber and its application. J. Tsinghua Univ. 1988, 28, 73-84.

9. Emadi, J.; Solemani, A. Maximum water hammer sensitivity analysis. World Acad. Sci. Eng. Technol. 2011, 73, $416-419$.

10. Wan, W.; Li, F. Sensitivity analysis of operational time differences for a pump-valve system on a water hammer response. J. Press. Vessel Technol. 2016, 138, 1-8. [CrossRef]

11. Diao, X.F.; Zhang, X.H.; Yang, Y.Y. Sensitivity analysis of restricted orifice in the hydropower station. In Proceedings of the 5th International Conference on Civil, Architectural and Hydraulic Engineering (ICCAHE 2016), Zhuhai, China, 30-31 July 2016.

12. Ramos, H.; Covas, D.; Borga, A.; Loureiro, D. Surge damping analysis in pipe systems: Modelling and experiments. J. Hydraul. Res. 2004, 42, 413-425. [CrossRef]

13. Yazdi, J.; Hokmabadi, A.; JaliliGhazizadeh, M.R. Optimal size and placement of water hammer protective devices in water conveyance pipelines. Water Resour. Manag. 2019, 33, 569-590. [CrossRef]

14. Vereide, K.; Richter, W.; Zenz, G.; Lia, L. Surge tank research in Austria and Norway. WasserWirtschaft 2015, 105, 58-62. [CrossRef]

15. Nabi, G.; Kashif, M.; Tariq, M. Hydraulic Transient Analysis of Surge Tanks: Case Study of Satpara and Golen Gol Hydropower Projects in Pakistan. Pak. J. Engg. Appl. Sci. 2011, 8, 34-48.

16. Liu, D.; Liu, Q. Volume calculation for upper chamber in double-chamber Surge Tank. Water Power 1993, 11, 36-39. 
17. Travaš, V. Water mass oscillations in a generic surge chamber. J. Croat. Assoc. Civ. Eng. 2014, 66, 323-334.

18. Chaudhry, M.H. Applied Hydraulic Transients; Van Nostrand Reinhold: New York, NY, USA, 1979; ISBN 0442215177.

19. Wylie, E.; Streeter, V.L.; Suo, L. Fluid Transients in Pipeline Systems; Prentice Hall: Englewood Cliffs, NJ, USA, 1992.

20. Bhattarai, K.P.; Zhou, J.; Palikhe, S.; Pandey, K.P.; Suwal, N. Numerical modeling and hydraulic optimization of a surge tank using particle swarm optimization. Water 2019, 11, 715. [CrossRef]

21. Bozkus, Z.; Calamak, M. Numerical Investigation of Operation Levels in a Surge Tank of a Small Hydropower Plant. In Proceedings of the 10th International Congress on Advances in Civil Engineering; Middle East Technical University, Ankara, Turkey, 17-19 October 2012.

22. Shani, T.; Gupta, T. Hydraulic transient flow analysis using Method of Characteristics. Int. J. Innov. Res. Sci. Eng. Technol. 2017, 6, 14812-14827.

23. Salmanzadeh, M.; Torfi, S. Analysis of surge in pipelines systems by characteristics method. Int. J. Mech. 2011, 5, 83-90.

24. Salmanzadeh, M. Numerical Method for Modeling Transient Flow in Distribution Systems. Int. J. Comput. Sci. Netw. Secur. 2013, 13, 72-78.

25. Martins, N.M.C.; Brunone, B.; Meniconi, S.; Ramos, H.M.; Covas, D.I.C. CFD and 1D approaches for the unsteady friction analysis of low Reynolds number turbulent flows. J. Hydraul. Eng. 2017, 143, 1-13. [CrossRef]

26. Kisan, M.; Sangathan, S.; Nehru, J.; Pitroda, S.G. IS 7396-1 (1985): Criteria for Hydraulic Design of Surge Tanks, Part 1: Simple, Restricted Orifice and Differential Surge Tanks; Bureau of Indian Standards: New Delhi, India, 1985.

27. Mosonyi, E. High-Head Power Plants, 3rd ed.; Akadémiai Kiadó: Budapest, Hungary, 1991.

28. Montes, J.S. Damping and stability of orifice plate surge tanks by approximate analytical technique. In Proceedings of the 7th Australasian Hydraulics and Fluid Mechanics Conference, Brisbane, Australia, 18-22 August 1980.

29. Thoma, D. Zur Theorie des Wasserschlosses bei selbsttätig geregelten Turbinenanlagen; Oldenbourg: Munchen, Germany, 1910.

30. Jaeger, C. Present Trends in Surge Tank Design. Proc. Inst. Mech. Eng. 1954, 168, 91-124. [CrossRef]

31. National Energy Administration of China. Design Code for Surge Chamber of Hydropower stations. China Electr. Power Press 2014, NB/T 35021. Available online: www.gong123.com/dianli/2016-09-16/1182918.html\# edown (accessed on 1 September 2019).

32. Kisan, M.; Sangathan, S.; Nehru, J.; Pitroda, S.G. IS 7396-3 (1990): Criteria for Hydraulic Design of Surge Tanks, Part 3: Special Surge Tanks; Bureau of Indian Standards: New Delhi, India, 1990.

33. Deb, K.; Pratap, A.; Agarwal, S.; Meyarivan, T. A fast and elitist multiobjective genetic algorithm: NSGA-II. IEEE Trans. Evol. Comput. 2002, 6, 182-197. [CrossRef]

34. Peng, W.; Zhang, Q.; Li, H. Comparison between MOEA/D and NSGA-II on the multi-objective travelling salesman problem. Stud. Comput. Intell. 2009, 171, 309-324.

35. Godnez, A.C.; Espinosa, L.E.M.; Montes, E.M. An experimental comparison of multiobjective algorithms: NSGA-II and OMOPSO. In Proceedings of the 2010 IEEE Electronics, Robotics and Automotive Mechanics Conference, Morelos, Mexico, 28 September-1 October 2010.

36. Kollat, J.B.; Reed, P.M. Comparison of multi-objective evolutionary algorithms for long-term monitoring design. In Proceedings of the World Water Congress 2005: Impacts of Global Climate Change Congress, Anchorage, Alaska, 15-19 May 2005.

37. Haghighipour, S.; Fathi-Moghadam, M. Optimization of hydropower conveyance systems. J. Food Agric. Environ. 2010, 8, 1093-1096.

38. Afshar, H.; Kerachian, R.; Bazargan-Lari, M.R.; Niktash, A.R. Developing a closing rule curve for valves in pipelines to control the water hammer impacts: Application of the NSGA-II optimization model. In Proceedings of the Pipelines Congress 2008-Pipeline Asset Management: Maximizing Performance of Our Pipeline Infrastructure, Atlanta, GA, USA, 22-27 July 2008.

39. Deb, K.; Miettinen, K. A review of nadir point estimation procedures using evolutionary approaches: A Tale of dimensionality reduction. In Proceedings of the 5th International Conference on Evolutionary Multi-Criterion Optimization, Nantes, France, 7-10 April 2009. 
40. Shukla, P.K.; Deb, K. On finding multiple Pareto-optimal solutions using classical and evolutionary generating methods. Eur. J. Oper. Res. 2007, 181, 1630-1652. [CrossRef]

41. Hannett, L.N. Modeling and control tuning of a hydro station with units sharing a common penstock section. IEEE Trans. Power Syst. 1999, 14, 1407-1414. [CrossRef]

42. Siu, T.K.; Nash, G.A.; Shawwash, Z.K. A practical hydro, dynamic unit commitment and loading model. IEEE Trans. Power Syst. 2001, 16, 301-306. [CrossRef]

(C) 2020 by the authors. Licensee MDPI, Basel, Switzerland. This article is an open access article distributed under the terms and conditions of the Creative Commons Attribution (CC BY) license (http://creativecommons.org/licenses/by/4.0/). 